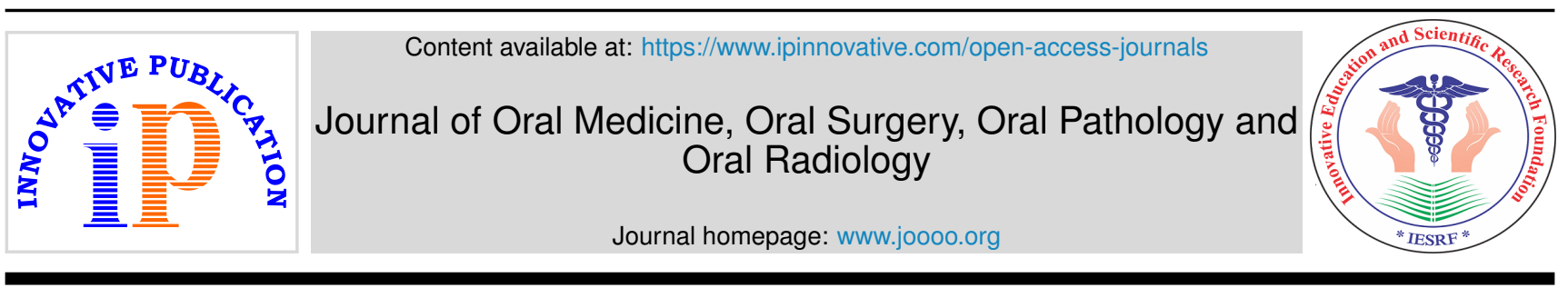

\title{
Editorial
}

\section{Oral squamous cell carcinoma, a potential risk factor for SARS-CoV-2 infection and COVID-19 associated complications}

\author{
Thodur Madapusi Balaji ${ }^{1}$, Saranya Varadarajan², Shankargouda Patil ${ }^{3}$, \\ A Thirumal Raj ${ }^{2, *}$ \\ ${ }^{1}$ Dept. of Dentistry, Bharathirajaa Hospital, and Research Institute, Chennai, Tamil Nadu, India \\ 2 Dept. of Oral Pathology and Microbiology, Sri Venkateswara Dental College and Hospital, Chennai, Tamil Nadu, India \\ ${ }^{3}$ Dept. of Maxillofacial Surgery and Diagnostic Sciences, Division of Oral Pathology, College of Dentistry, Jazan University, \\ Jazan, Saudi Arabia
}

\section{A R T I C L E I N F O}

Article history:

Received 27-10-2020

Accepted 29-10-2020

Available online 02-11-2020 (c) This is an open access article distributed under the terms of the Creative Commons Attribution License (https://creativecommons.org/licenses/by/4.0/) which permits unrestricted use, distribution, and reproduction in any medium, provided the original author and source are credited.
The recent outbreak of the COVID 19 pandemic has caused untold anxiety and a threat to human life. It is caused by the SARS-CoV-2 Virus belonging to the coronaviridae family. ${ }^{1}$ The disease spreads by droplet transmission from person to person. As at present there are no specific drug or vaccine available, social distancing along with good hygiene practices are the need of the hour to prevent the disease spread. It has been reported that the prognosis of the disease is poor in the case of associated comorbidity such as diabetes, ${ }^{2}$ hypertension, ${ }^{3}$ and malignancy. ${ }^{4}$

Oral squamous cell carcinoma (OSCC) is ranked as the $6^{\text {th }}$ most common malignant worldwide. ${ }^{5}$ Although the disease is multifactorial in etiology, tobacco and alcohol have been proposed as the major risk factors. ${ }^{6}$ It is a well-known fact that several molecular pathways are altered in oral carcinogenesis causing overexpression of various proteins such as EMMPRIN, ${ }^{7}$ TMPRSS, ${ }^{8}$ Furin, ${ }^{9}$ and Cathepsin L. ${ }^{10}$ It has been hypothesized that these molecules could facilitate SARS Cov- 2 entry into the host. ${ }^{11}$ Hence oral squamous cell carcinoma could be considered a predisposing factor for SARS Cov- 2 infections. In addition to the plethora of molecules overexpressed in OSCC/oral cancer, the role of

\footnotetext{
* Corresponding author.

E-mail address: thirumalraj666@gmail.com (A. T. Raj).
}

inflammasomes in the pathobiology and progression of oral cancer deserve mention at this juncture. Danger signals of endogenous origins elicit an immune response in form of inflammasomes, which are a large complex of multiple proteins capable of signaling. These inflammasomes are located in the cell's cytosol and are capable of caspase-1 (inflammatory protease) upregulation. They can also cleave the interleukin (IL)- $1 \beta$ and pro-IL-18 (proinflammatory cytokines) to their respective active forms, thereby initiating pyroptosis. ${ }^{12}$ Nod-like receptor (NLR), the adapter apoptosis-associated speck-like (ASC) protein, and Caspase- 1 constitute the inflammasome complex. Nodlike receptor protein 3 (NLRP3), is an NLR protein family member and is in turn comprised of 22 members. ${ }^{13,14}$ NLRP3 responds to several infectious and endogenous ligands. Thus, NLRP3 dysregulation is a vital part of the molecular biology of numerous pathologies both inflammatory and tumorigenic nature. Inflammation is a strength linked to genetic and epigenetic changes capable of inducing OSCC. ${ }^{15}$ Upregulated NLRP3 inflammasome has been reported in both animal OSCC model and human OSCC cases. Hence it is anticipated that patients with OSCC could have higher levels of circulating proinflammatory cytokines such as IL 1 beta and IL 6 as a consequence of NLRP3 activation. Further evidence for the 
same is obtained from clinical studies that have assessed circulating proinflammatory cytokines in OSCC patients. ${ }^{16}$

It is also noteworthy that the NLRP3 inflammasome is activated in SARS-Cov 2 infection. ${ }^{17}$ In sequela of SARSCov 2 infection such as acute respiratory distress syndrome and acute lung injury, NLRP3 activation has been implicated as a major source of aberrant cytokine production which finally culminates in multi-organ injury and morbidity. ${ }^{18}$ It has been postulated that the injury of cells bearing the Angiotensin-converting enzyme 2 (ACE 2) leads to dysregulated NLRP3 activation. ${ }^{19}$ Interestingly, the ACE 2 enzyme is a receptor for binding and entry of SARS Cov 2 into the human host. ${ }^{20}$ In this scenario, it could be hypothesized that a patient having OSCC and SARS Cov 2 infection is at high risk for SARS Cov 2 complications due to increased NLRP3 activation as this phenomenon occurs in both the above conditions. Hence it is expected that a patient with OSCC and SARS Cov 2 will have very high levels of circulating cytokines and is hence vulnerable to multi-organ failure. It is hence suggested that patients with OSCC should be utmost careful considering the vital complications they could suffer if they contract SARS Cov2. This situation is also a red flag alert to dental surgeons, oral pathologists, and oral surgeons who regularly screen and treat OSCC patients.

\section{Conflict of Interest}

None.

\section{References}

1. Gorbalenya A, Baker S, Baric R. Coronaviridae Study Group of the International Committee on Taxonomy of Viruses. The species Severe acute respiratory syndrome-related coronavirus: classifying 2019-nCoV and naming it SARS-CoV-2. Nat Microbiol. 2020;5:53644. त01:01038/s41564-020-0645-7.

2. Das S, Anu KR, Birangal SR, Nikam AN, Pandey A, Mutalik $\mathrm{S}$, et al. Role of comorbidities like diabetes on severe acute respiratory syndrome coronavirus-2: A review. Life Sci. 2020;258. do1:10.1016/1.115.2020.118202.

3. Singh AK, Gupta R, Misra A. Comorbidities in COVID-19: Outcomes in hypertensive cohort and controversies with renin angiotensin system blockers. Diabetes Metab Syndr Clin ResRev. 2020;14(4):283-7. doi:10.1016/j.dsx.2020.03.016

4. Jarahzadeh MH, Asadian F, Farbod M, Meibodi B, Abbasi H, Jafari $\mathrm{M}$, et al. Cancer and Coronavirus Disease (COVID-19): Comorbidity, Mechanical Ventilation, and Death Risk. J Gastrointest Cancer.

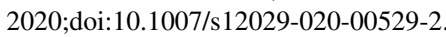

5. Markopoulos AK. Current Aspects on Oral Squamous Cell Carcinoma. Open Dent J. 2012;6(1):126-30. doi: $10.2174 / 874210601206010226$.

6. Blot WJ, Mclaughlin JK, Winn DM, Austin DF, Greenberg RS, Preston-Martin S. Smoking and drinking in relation to oral and pharyngeal cancer. Cancer Res. 1988;48:3282-9.

7. Vigneswaran N, Beckers S, Waigel S, Mensah J, Wu J, Mo J. Increased EMMPRIN (CD 147) expression during oral carcinogenesis. Exp Mol Pathol. 2006;80(2):147-59. [01:10.1016/].yexmp.2005.09.01].
8. Lam DK, Dang D, Flynn AN, Hardt M, Schmidt BL. TMPRSS2, a novel membrane-anchored mediator in cancer pain. Pain 2015;156(5):923-30. doi:10.1097/1.pain.0000000000000130

9. Cicco RD, Bassi DE, Page R, Klein-Szanto AJ. Furin expression in squamous cell carcinomas of the oral cavity and other sites evaluated by tissue microarray technology. Acta Odontol Latinoam. 2002;15:29-37.

10. Macabeo-Ong M, Shiboski CH, Silverman S, Ginzinger DG, Dekker $\mathrm{N}$, Wong DTW, et al. Quantitative analysis of cathepsin L mRNA and protein expression during oral cancer progression. Oral Oncol. 2003;39(7):638-47. doi:10.1016/s 1368-8375(03)00034-4.

11. Balaji TM, Varadarajan S, Rao USV, Raj AT, Patil S, Arakeri G, et al. Oral cancer and periodontal disease increase the risk of COVID 19? A mechanism mediated through furin and cathepsin overexpression. Med Hypotheses. 2020;144:109936. do1:10.1016/].mehy.2020.109936.

12. Lamkanfi M, Dixit VM. Mechanisms and Functions of Inflammasomes. Cell. 2014;157(5):1013-22. 101:10.1016/1.cell.2014.04.007

13. Ting JPY, Lovering RC, Alnemri ES, Bertin J, Boss JM, Davis BK, et al. The NLR Gene Family: A Standard Nomenclature. Immun. 2008;28(3):285-7. [01:10.1016/].1mmun1.2008.02.005.

14. Place DE, Kanneganti TD. Recent advances in inflammasome biology. Curr Opin Immunol. 2018;50:32-8. [01:10.1016/].c01.2017.10.01].

15. Kumar A, Sarode SC, Sarode GS, Majumdar B, Patil S, Sharma NK. Beyond gene dictation in oral squamous cell carcinoma progression and its therapeutic implications. Transl Res Oral Oncol. 2017;2.

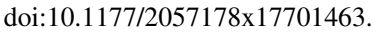

16. Brailo V, Vucicevic-Boras V, Lukac J, Biocina-Lukenda D, AlajbegZilic I, Milenovic A, et al. Salivary and serum interleukin 1 beta, interleukin 6 and tumor necrosis factor alpha in patients with leukoplakia and oral cancer. Med Oral Patol Oral y Cir Bucal. 2012;2012:e10-5. doi: $0.43 / 7 /$ medoral.173231

17. Freeman TL, Swartz TH. Targeting the NLRP3 Inflammasome in Severe COVID-19. Front Immunol. 2020;11. dor:-103380/6mmu20200/5/8.

18. Ganter MT, Roux J, Miyazawa B, Howard M, Frank JA, Su G, et al. Interleukin- $1 \beta$ Causes Acute Lung Injury via $\alpha \mathrm{v} \beta 5$ and $\alpha \mathrm{v} \beta 6$ Integrin-Dependent Mechanisms. Circ Res. 2008;102(7):804-12. doi-10) 16 /circresaha 10716067

19. Chen IY, Moriyama M, Chang MF, Ichinohe T. Severe Acute Respiratory Syndrome Coronavirus Viroporin 3a Activates the NLRP3 Inflammasome. Front Microbiol. 2019;10. dol: $103389 / 4 m i c h 201000050$.

20. Xu H, Zhong L, Deng J, Peng J, Dan H, Zeng X, et al. High expression of ACE2 receptor of 2019-nCoV on the epithelial cells of oral mucosa. Int J Oral Sci. 2020;12(1). 100:10.1038/s41368-(020-0074-x.

\section{Author biography}

Thodur Madapusi Balaji, Senior Consultant and Head

Saranya Varadarajan, Senior Lecturer

Shankargouda Patil, Associate Professor

A Thirumal Raj, Senior Lecturer

Cite this article: Balaji TM, Varadarajan S, Patil S, Raj AT. Oral squamous cell carcinoma, a potential risk factor for SARS-CoV-2 infection and COVID-19 associated complications. J Oral Med, Oral Surg, Oral Pathol, Oral Radiol 2020;6(4):166-167. 